\title{
Airway spray efficacy of local anesthetic with fiberscope
}

\author{
Yu-Hui Wang ${ }^{1} \cdot$ Fu-Shan Xue ${ }^{1} \cdot$ Hui-Xian $\mathrm{Li}^{1}$
}

Received: 16 March 2017 / Accepted: 17 March 2017 / Published online: 27 March 2017

(C) Japanese Society of Anesthesiologists 2017

\section{To the Editor:}

In the recent article by Tsukamoto et al. [1] assessing airway spray efficacy of local anesthetic with a fiberscope, an important issue ignored by them is the fact that the spreading of local anesthetic in the airway is achieved mainly by a patient's coughing immediately after injection, whereas a manikin has no coughing reflexes. In method, it was unclear whether injection velocity of liquid and air mixture was comparable with different syringes, though this factor can significantly affect the spray efficacy of local anesthetic in the airway [2]. These issues would have made the interpretation of their findings questionable.

The main aim of injecting local anesthetic and air mixture is to ensure that all of the injected solution is ejected from the working channel and adequate spreading of the injected solution onto the target airway mucosa is achieved. In fact, the method used most commonly in clinical practice is that $1 \mathrm{ml}$ of solution plus $9 \mathrm{ml}$ air in a 10-ml syringe is injected with each spray and a second $10 \mathrm{ml}$ of air is given immediately after first injection [2]. A multiorifice epidural catheter through the working channel can also avoid losing any of the injected solution, provide multidirectional sprays of local anesthetic, and reduce the stimuli to the airway in awake patients as the fiberscope's tip is positioned above the glottis and airway spray is completed using the epidural catheter with fiberoptic visualization [3].

\section{Compliance with ethical standards}

Conflict of interest None of authors has received financial support and there are no potential conflicts of interest for this work.

\section{References}

1. Tsukamoto M, Hirokawa J, Yokoyama T. Effective spray for topical anesthesia with fiberscope. J Anesth. 2017. doi:10.1007/ s00540-017-2331-5.

2. Simmons ST, Schleich AR. Airway regional anesthesia for awake fiberoptic intubation. Reg Anesth Pain Med. 2002;27:180-92.

3. Long TR, Wass CT. An alternative to transtracheal injection for fiberoptic intubation in awake patients: a novel noninvasive technique using a standard multiorifice epidural catheter through the bronchoscope suction port. Anesthesiology. 2004;101:1253.
This comment refers to the article available at doi:10.1007/ s00540-017-2331-5.

Fu-Shan Xue xuefushan@aliyun.com

1 Department of Anesthesiology, Plastic Surgery Hospital, Chinese Academy of Medical Sciences and Peking Union Medical College, 33 Ba-Da-Chu Road, Shi-Jing-Shan District, Beijing 100144, People's Republic of China 